\title{
MÉTODOS DIFERENCIADOS DE RESOLUÇÃO DE CONFLITOS E ENSINO JURÍDICO: ANÁLISE A PARTIR DAS GRADES CURRICULARES DOS CURSOS DE GRADUAÇÃO EM DIREITO EM SERGIPE
}

\author{
DIFFERENT METHODS OF CONFLICT RESOLUTION AND GRADUATION IN \\ LAW: ANALYSIS FROM GRADES OF CURRICULUM COURSE GRADUATION \\ IN RIGHT IN SERGIPE
}

\author{
${ }^{1}$ Antonio Henrique de Almeida Santos
}

\section{RESUMO}

Este trabalho tem por objeto de estudo os métodos diferenciados de resolução de conflitos e seu impacto no ensino jurídico, em especial nos cursos de graduação em direito em Sergipe. A relevância do tema revela-se tanto no campo teórico quanto no pragmático. Parte-se da análise do princípio do acesso à justiça, sua evolução histórica e sua conceituação atual. A idéia basilar do estudo é refletir se e em que medida o estudo dos métodos diferenciados de resolução de conflitos nos cursos de graduação em direito impactam na cultura jurídica e, em especial, na efetivação do princípio do acesso à justiça. Para isso, a análise é feita a partir de ensinamentos doutrinários acerca do aludido princípio e seus desdobramentos tanto com a utilização do método tradicional, jurisdicional contencioso, de resolução de conflitos, quanto com os meios alternativos. Analisam-se as grades curriculares dos cursos de graduação em direito em Sergipe, concluído-se pela pouca importância dada ao tema pela maioria das instituições de ensino superior do estado. Ao fim, propõe-se como necessidade à concretização do princípio do acesso à justiça, a modificação na abordagem do tema nos cursos de graduação. O presente estudo, nesse aspecto, contribui com uma nova visão do assunto, possível de ser adotado nas instituições de ensino superior e com maior consonância com as Diretrizes Curriculares Nacionais, referentes ao curso de graduação em direito.

Palavras-chave: Ensino jurídico, Métodos diferenciados de resolução de conflitos, Acesso à justiça, Abordagem educacional concretizadora de direitos

\footnotetext{
${ }^{1}$ Graduado em Direito Processual pela Universidade Estadual do Sudoeste da Bahia, Itapetinga - BA (Brasil). Professor da Faculdade de Administração e Negócios de Sergipe - FANESE, Aracaju - SE (Brasil).

E-mail: antonio.henrique69@gmail.com
} 


\begin{abstract}
This work has as object of study the different methods of conflict resolution and its impact on education legal, especially in undergraduate courses in law in Sergipe. The relevance of the subject is revealed both in the theoretical field and in pragmatic. It starts with the analysis of the principle of access to justice, its historical evolution and current concept. The basic idea of the study is to reflect whether and to what extent the study of different methods of resolving conflicts in law in undergraduate programs impact the legal culture and in particular the realization of the principle of access to justice. For this, the analysis is done from doctrinal teachings on the aforementioned principle and its consequences both using the traditional method, jurisdictional litigation, dispute resolution, as with alternative methods. The curricula of law in undergraduate courses are analyzed in Sergipe, completed by the little importance given to the subject by most higher state educational institutions. At the end, it is proposed as a need for implementation of the principle of access to justice, the change in approach to the subject in undergraduate courses. This study, in this respect, contributes a new vision of the subject, it can be adopted in higher education institutions and more consistent with the National Curriculum Guidelines for the undergraduate degree in law.
\end{abstract}

Keywords: Legal education, Differentiated methods of conflict resolution, Access to justice. educational approach able to materialize righ 


\section{INTRODUÇÃO}

Os cursos de graduação em direito são regulamentados parcialmente pela Câmara de Educação Superior - CES, ligada ao Conselho Nacional de Educação - CNE do Ministério da Educação. Cabe à CES instituir as Diretrizes Curriculares Nacionais que, como já se infere do próprio nome, traça de modo geral os vetores educacionais a serem seguidos pelas Instituições de Ensino Superior - IES. Estas, por sua vez, podem organizar os currículos de seus cursos através de seus projetos pedagógicos. Como se vê, as IES possuem razoável liberdade na elaboração de suas grades curriculares, devendo estar, evidentemente, de acordo com as Diretrizes Curriculares Nacionais.

As Diretrizes estatui, entre outras, a necessidade de estudo dos diversos ramos do direito no contexto da evolução da Ciência Jurídica. E embora sem descer a minúcias, mesmo porque não é seu papel, revela-se necessário interpretar essa norma com o intuito de efetivar nos cursos de graduação em direito o estudo atual do estado da arte da Ciência Jurídica. É nesse caminho que se propõe o presente estudo.

O trabalho inicia com breves comentários acerca do princípio do Acesso à Justiça, apontando o atual estágio de desenvolvimento conceitual do aludido princípio. Apresenta-se um resumo da evolução histórica da interpretação dada ao instituto para desaguar na visão contemporânea, inserindo a necessidade de utilização de métodos diferenciados de resolução de conflitos para sua concreta efetivação.

Segue com alguns apontamentos acerca do conceito de conflito, especificamente de seu conteúdo jurídico, para constatar que é um fenômeno ínsito à existência do homem e da sociedade humana. Introduz-se o papel do Poder Judiciário como instituição protagonista na resolução dos conflitos, reconhecendo-se, todavia, a necessidade de se suplantar esse modelo histórico ou, quando menos, reconhecer outros métodos e instituições importantes nesse desiderato.

Faz-se uma análise acerca da aplicação e evolução dos métodos alternativos de solução de conflitos no Brasil, comprando-se com alguns outros países.

$\mathrm{Na}$ segunda parte do estudo, apresenta-se o paradigma atual corrente nos cursos de graduação em direito, no que pertine à forma de abordagem e estudo de métodos de solução de conflitos, cotejando-se com as normas regentes do ensino jurídico no país. 
Continua-se com a demonstração do atual panorama do estudo dos métodos diferenciados de resolução de conflitos no Brasil, feito a partir de estudo já publicado e em Sergipe, com constatação de pesquisa feita pelo próprio autor, onde se verifica a deficiência no estudo desses métodos nos cursos de graduação.

Procura-se, em seguida, demonstrar a diferença entre as competências e habilidades necessárias para formação do profissional apto a atuar em um processo jurisdicional contencioso e em procedimentos que se utilizem de métodos diferenciados de solução de conflitos, apresentando-se as competências e habilidades necessárias a estes métodos, especialmente à mediação.

Por fim, apresenta-se uma conclusão de abordagem crítica, de viés jurídico e pedagógico, propondo-se a necessidade de se rever os atuais paradigmas educacionais relacionados ao tema em estudo, a fim de fomentar uma mudança de cultura jurídica necessária à efetivação do princípio do Acesso à Justiça.

\section{ACESSO À JUSTIÇA E MÉTODOS DIFERENCIADOS DE RESOLUÇÃO DE CONFLITOS}

\subsection{O princípio do Acesso à Justiça}

A doutrina costuma apontar três períodos do movimento de acesso à justiça (AZEVEDO, 2013, p. 38). Em um primeiro momento, o acesso à justiça era tido como mero acesso ao Poder Judiciário. O simples ajuizamento uma ação judicial, com possibilidade de resposta, já indicaria a concreção do princípio do acesso à justiça. No período seguinte, constatada a insuficiência do ingresso no Judiciário para configuração efetiva do aludido princípio, passa-se a ver o acesso à justiça como o acesso ao Judiciário com resposta tempestiva. Ao Judiciário cabe dar a resposta em tempo razoável ao cidadão que ingressou na justiça e não apenas permitir e/ou facilitar o seu ingresso. E no terceiro período, momento do atual estado da arte acerca do tema, visualiza-se o acesso à justiça a partir de uma solução efetiva e adequada para o conflito, por via de uma participação do Estado.

É nesse terceiro momento histórico que se passa a constatar com a devida ênfase a necessidade de se incluir jurisdicionados que até então estão alijados do sistema de justiça. Para alguns, com desdobramentos ainda mais largos que a ideia corrente de acesso à justiça como acesso à justiça a ser entregue pelo Poder Judiciário, mas também como possibilidade de 
concretização de políticas públicas voltadas não só ao aspecto jurídico, mas igualmente aos campos econômico e social. Nesse tom, é que leciona Sadek (2009, p. 170) quando afirma “que o acesso à justiça se constitui na porta de entrada para a participação nos bens e serviços de uma sociedade." O argumento é de que não há possibilidade de efetivação de políticas públicas de inclusão sem garantias que permitam um efetivo e concreto acesso à justiça.

Com esse mote, entendendo acesso à justiça de forma mais abrangente que acesso ao Judiciário, mesmo em se considerando o acesso ao Judiciário com entrega tempestiva e efetiva da jurisdição, é que se colocam os meios não jurisdicionais ou não contenciosos de resolução de conflitos como métodos necessários e eficazes ao acesso à justiça. E é nesse ponto que se apresenta o motivo da reflexão que ora se propõe: Os métodos diferenciados de resolução de conflitos e a necessidade de seu estudo nos cursos de graduação em Direito.

A opção pela nomenclatura métodos diferenciados de resolução de conflitos, liga-se ao entendimento ainda atual em ver o processo jurisdicional contencioso como o método ordinário e os demais como alternativos ou diferenciados.

\subsection{O Conflito e os Métodos diferenciados de resolução}

Antes de pontuar as formas de solução de conflitos, afigura-se importante alguma palavra acerca do que seja o conflito e sua importância na esfera do Direito.

O conflito é inerente à vida social. Não há sociedade sem conflito. "É normal nos relacionamentos humanos e é um motor de mudanças.”(LEDERACH, 2012, p. 17)

Em sentido etimológico, conflito provém do latim "conflicto", a significar embate, choque, antagonismo, oposição. Entre as várias definições da palavra encontráveis no dicionário Michaelis, pode-se destacar a "tensão produzida pela presença simultânea de motivos contraditórios; incompatibilidade entre valores culturais cujos portadores humanos estabelecem contato.” Já Abbagnano (2014, p. 205) pretende explicar conflito como sendo "contradição, oposição ou luta de princípios, propostas ou atitudes." Como se observa, é ínsita à palavra conflito a idéia de disputa de interesses, antagonismo entre o pensar e/ou o agir de ao menos dois indivíduos. E, conforme afirmado, é um fenômeno psicológico/social imanente ao ser humano e à vida em sociedade. Em uma proposição: não há sociedade onde não exista conflito.

A partir dessa realidade intrínseca à vida social, o homem desde o início de sua jornada gregária procura criar mecanismos para resolver ou administrar os conflitos. Passado 
o momento da força bruta "acendem-se as primeiras luzes: surgem as leis, inicialmente morais depois jurídicas. Regras de conduta que reprimem os instintos, a barbárie, disciplinam as relações interpessoais [...] Tem início o processo civilizatório.”(BARROSO, 2013, p. 25). O direito surge e, tempos depois, consolida-se como o lócus para a administração das disputas sociais.

É só no estado moderno, com Montesquieu a afirmar a necessidade de separação dos principais poderes estatais em órgãos distintos, que o Judiciário aparece como entidade principal e última na solução dos conflitos e aplicação do direito. Sua ferramenta para cumprir esse desiderato é o processo. Em sua forma principal: processo jurisdicional contencioso. Esse é ainda no estado brasileiro tido como o modo ordinário de solução de conflitos, tanto que a doutrina especializada costuma referir-se a outros meios de alternativos, a exemplo do que leciona Santos (1998, p. 120) quando afirma que "os sistemas jurídicos estabelecem, atualmente, a precedência dos Poderes Judiciários para dirimir litígios, mas possibilitam situações em que os conflitos possam vir a ser solucionados através de mecanismos alternativos de composição." Como visto, o só fato de a doutrina referir-se a outros métodos de solução de conflitos como alternativos, já revela o entendimento pela sua subsidiariedade em relação a um outro método, dito principal.

Não obstante a apontada primazia do processo contencioso e do Poder Judiciário na resolução dos conflitos, outros existem e vêm sendo cada vez mais utilizados no país. E embora não seja objeto deste trabalho a definição e delimitação de métodos extrajudiciais e/ou alternativos de resolução de controvérsias. Revela-se importante alguma palavra sobre o tema a fim de melhor situar o presente artigo.

Um método autocompositivo de resolução de conflitos é a negociação, onde as próprias pessoas envolvidas na contenda expõem seus pontos de vista e debatem até que possam chegar a um consenso apto a por fim ao problema, sem a necessidade de participação de terceiro.

Destacam-se ainda, entre o métodos diferenciados ou alternativos de resolução de conflito a arbitragem, conciliação e a mediação.

A arbitragem, assim como o processo jurisdicional, é um modelo contencioso onde um terceiro decide baseado em um procedimento com regras algo rígidas e pré-definidas, pondo fim à controvérsia. No Brasil a lei de regência do instituto da arbitragem é a número 9.307/1996. Referida norma restringe seu âmbito de aplicação às questões referentes a direito patrimonial disponível entre pessoas capazes. Exclui, portanto, desse meio de solução de conflito as contendas de ordem não patrimonial, ainda que se trate de direitos disponíveis e, 
por outro lado, os de índole patrimonial que não sejam disponíveis, a exemplo de questões relacionadas a bens públicos.

No caso da conciliação, pode tanto ser utilizado como um método a ser aplicado de modo isolado, como também fazendo parte de um rito mais abrangente, inclusive contencioso. Por esse método, um terceiro utiliza-se de técnicas específicas em um procedimento próprio, a fim de auxiliar os contendores a chegar a um acordo.

A mediação, há também a participação de um terceiro que auxilia as partes a encontrar uma solução que seja a melhor para ambos. Pode-se afirmar que é, em certa medida, um procedimento mais elaborado que a conciliação, pois visa a transformação ou resolução do conflito também no aspecto sociológico. Para isso deve valer-se de mediadores capacitados e procedimento específico que, via de regra, não se exaure em um só momento. Ao contrário, a regra é que vários encontros sejam necessários antes de se chegar a um bom termo para o conflito.

Embora esses métodos venham crescendo em importância e aplicação prática nos últimos anos no Brasil, é fato que ainda é tímida sua utilização quer se comparado ao método tradicional processual de solução de conflitos no plano interno nacional, quer se comparado a outros países como Argentina e Estados Unidos da América, para citar apenas dois exemplos.

$\mathrm{Na}$ Argentina, desde a promulgação da Lei. No 24.573/2005 é necessário que a parte comprove já ter tentado resolver o conflito através da mediação para ser admitido a ajuizamento de ação no Judiciário. Entretanto, Nascimento (2011) afirma que a mediação já vem sendo utilizada como forma de solução de controvérsias desde 1995, asseverando ainda que estudos apontam que mais da metade dos conflitos naquele país são resolvidos através deste método.

De igual modo o desenvolvimento da mediação nos Estados Unidos da América vem sendo posto em prática, segundo Barbado(2004), há mais de cinquenta anos, tanto no plano acadêmico quanto prático, tendo-se intensificado sua institucionalização nos últimos quinze anos com grande sucesso, diferentemente do que ocorre no Brasil.

\subsection{Os Métodos diferenciados de resolução de conflitos no Brasil.}

Não obstante, observa-se que os métodos diferenciados de resolução de conflitos ou meios de administração e solução de conflitos fora do âmbito do processo jurisdicional contencioso vêm ganhando corpo no Brasil nos últimos anos. Conforme já visto, foi a Lei 9.307/1996, Lei da Arbitragem que inaugurou esse movimento no campo legislativo. 
Especialmente no que se refere a normas acerca da mediação e conciliação foi a Resolução nº 125/2010 do Conselho Nacional de Justiça - CNJ. A Resolução refere-se a política judiciária nacional de tratamento adequado dos conflitos no âmbito do Poder Judiciário. Entre outros dispositivos, estatui que cabe ao próprio CNJ a organização de programa inclinado à promoção de ações de incentivo à autocomposição de litígios e à pacificação social por meio da conciliação e mediação, que deverá ser implementado por todos os órgãos do Poder Judiciário, e outras entidades, inclusive universidades e outras instituições de ensino; determina a criação de núcleos permanentes de métodos consensuais de solução de conflitos em todos os Tribunais, além dos centros judiciais de solução de conflitos e cidadania; traça regras acerca da formação de conciliadores e mediadores e cria o Portal da Conciliação junto ao seu sítio na rede mundial de computadores.

No mesmo sentido, o Novo Código de Processo Civil, Lei nº 13.115/2015, traz várias regras acerca de conciliação e mediação. Já em seu artigo $3^{\circ}$ prescreve a necessidade de o Estado promover, sempre que possível, a solução conciliada dos conflitos e preconiza que os principais atores do sistema de acesso à justiça, juízes, advogados, defensores públicos e membros do Ministério Público devem estimular a solução dos conflitos por meio de métodos de solução consensual, a exemplo da conciliação e mediação.

O Novo Código de Processo Civil traz ainda diretrizes de criação pelos Tribunais de centros de judiciários de solução consensual de conflitos, indo ao encontro do já estatuído pela supracitada resolução $\mathrm{n}^{\circ}$ 125/2010 do CNJ. A nova lei coloca a conciliação e mediação como ponto fulcral do processo, determinando em vários artigos a busca da solução dos litígios por essas vias, com previsão de audiências necessárias para tentativa de conciliação ou mediação.

Note-se que o novo Código inclui a conciliação e mediação como etapas possíveis do processo jurisdicional contencioso, embora, como já explicitado, não há necessidade de ser dessa maneira.

Por fim, a recente Lei $\mathrm{n}^{\mathrm{o}}$ 13.140/2015, publicada em 29 de junho de 2015, dispõe especificamente sobre a mediação, com regras acerca dos princípios norteadores do instituto, dos mediadores, procedimentos de mediação judicial e extrajudicial, além da autocomposição de conflitos quando for parte a pessoa jurídica.

Interessante ressaltar a distinção que a lei fez acerca daqueles que podem ser mediadores extrajudiciais dos mediadores judiciais. Àqueles a lei não prescreveu nenhum requisito específico no que toca à sua formação. Limitou-se a dispor que a pessoa deve ser capaz, 
ter a confiança das partes e ser capacitada para fazer mediação. Sem embargo dessa última prescrição, não define o que é ser capacitada para fazer mediação. Já no que pertine ao mediador judicial, e lei foi mais específica. Com efeito, além da capacidade, o mediador judicial há de ter formação em ensino superior com graduação há pelo menos dois anos, além de obter capacitação em escola ou instituição de formação de mediadores, com reconhecimento da Escola Nacional de Formação e Aperfeiçoamento de Magistrados - ENFAM ou pelos tribunais. E o reconhecimento deverá observar requisitos mínimos estabelecidos em conjunto pelo Conselho Nacional de Justiça - CNJ e Ministério da Justiça.

Observa-se nessas prescrições uma nítida importância dada pela lei à formação e capacitação do mediador.

\section{O ESTUDO DOS MÉTODOS DIFERENCIADOS DE RESOLUÇÃO DE CONFLITOS NO ENSINO SUPERIOR NO BRASIL}

\subsection{Breves apontamentos para delimitação do estudo.}

Como visto, o crescente interesse pelos métodos diferenciados de resolução de conflitos no Brasil, que se apresenta através da inovação normativa tanto no âmbito administrativo (Resolução 125 do CNJ), quanto legislativo (Lei de Arbitragem, Novo Código de Processo Civil e Lei de Mediação); evocam a necessidade de estudo e pesquisa acerca do tema, no sentido de subsidiar a necessária capacitação de profissionais da área. É nesse sentido que este estudo pretende investigar se e em que medida o estudo das matérias pertinentes a este tema estão sendo vivenciados nos cursos de graduação em direito, especialmente no estado de Sergipe.

Conforme consta no final de seu livro "A Luta pelo Direito", Ihering afirma que "Só deve merecer a liberdade e a vida quem para as conservar luta constantemente" (IHERING, 2004, p. 91). O vocábulo 'luta', então, encontra-se tão radicalmente imbricado ao Direito, ao menos à ideia de Direito ensinada nas academias, que parece impossível alcançar-se o Direito sem luta. Essa, aliás, é a ideia central de Ihering em seu famoso opúsculo. Sendo a paz o escopo do Direito, tem na luta sua ferramenta essencial. Esse o lema e o legado do pensador Germânico. Esse parece ainda ser o norte do ensino jurídico no Brasil. E essa diretriz acadêmica responsável pela formação belicosa, demandista dos profissionais do direito, deságua, evidentemente, nos 
diversos espaços ocupados por eles. Seja, nos fóruns, escritórios de advocacia, delegacias etc. Não obstante, conforme já ressaltado, recentes estudos, práticas e mesmo criações normativas têm contribuído para uma mudança nesse paradigma, no sentido de constatar a existência, necessidade e eficácia de utilização de outros modelos de resolução de conflitos, não necessariamente a partir do embate. Em suma, parece que a luta não é mais a única, quiçá nem a mais eficiente, forma de se alcançar o Direito.

É nesse mesmo sentido a constatação de Egger (2008), quando critica necessidade da descoberta da verdade pelo juiz como uma ficção decorrente da suposta cientificidade a partir da concepção jurídica de modernidade baseada no litígio, desprezando, por vezes a vontade e o interesse das partes. E propõe a mediação como um método a contrapor o tradicional, devendo “a princípio, deixar de lado as principais funções operativas, míticas e políticas do sistema jurídico; em seu lugar, surge a referência a uma resolução dos conflitos que atende a uma satisfação de todas as partes e que estaria baseada em uma proposta auto- reguladora."(Egger, 2008, p. 164)

É oportuno afirmar, entretanto que não se tem até aqui subsídios para afirmar em que medida o foco no conflito e em sua tentativa de resolução através do processo contencioso, da maneira que se estuda nas academias jurídicas, influencia no, até então, pouco uso dos métodos diferenciados de resolução de conflitos no Brasil. E não é esse o objeto do presente trabalho, até porque demandaria estudos e pesquisas de cunho sociológico que fugiria ao que se propõe. Entretanto, afigura-se razoável a afirmação da necessidade de se possuir e, portanto, ter que se aprender competências específicas para bem utilizar esses métodos. Igualmente não se pretende com esse trabalho aferir se o estudo dos métodos diferenciados de resolução de conflitos nas faculdades de direito seria suficiente para modificar essas competências. O que se pretende é verificar o que se estuda nos dias atuais nos cursos de graduação em direito, especialmente no estado de Sergipe, em relação ao tema e, a partir dessa constatação, apresentar uma reflexão das possíveis conseqüências para o futuro da aplicação desses métodos.

\subsection{As normas referentes ao ensino no Brasil - $O$ curso de graduação em direito.}

Antes de pretender analisar o que se estuda e o que não se estuda na graduação em direito, é pertinente se verificar o que, segundo as normas de regência, pode e/ou deve ser estudado. 
Dada a profusão de normas existentes no Brasil, inclusive advindas de fontes distintas e de diferentes graus hierárquicos, não é fácil fazer uma análise acerca daquelas aplicáveis ao ensino jurídico, especificamente aos cursos de graduação em direito, objeto deste estudo.

A respeito do ensino universitário, a própria Constituição já estatui diretrizes quando, em seu artigo 22, XXIV, dispõe acerca da competência privativa da União para legislar sobre diretrizes e bases da educação nacional. Também os estados e o Distrito Federal têm competência para legislar sobre educação (art. 24. IX), bem como, juntamente com os municípios, possuem competência comum para proporcionar meios de acesso à educação (art. $23, \mathrm{~V})$.

Por seu turno, o artigo 207 da Constituição outorga às universidades autonomia didático-científica, o que, observadas as demais normas superiores referentes ao tema, as incluem como possíveis criadoras de normas dentro de seu espectro de autuação.

No plano infra-constitucional destaca-se a Lei $\mathrm{n}^{\circ}$ 9.394/1996, conhecida como Lei de Diretrizes e Bases da Educação - LDB. Em seu artigo 43 especifica a finalidade da educação superior, em resumo, estimular o desenvolvimento do espírito científico, formar em várias áreas do conhecimento profissionais aptos a participar do desenvolvimento da sociedade, incentivar a pesquisa e promover a extensão com vistas à difusão do conhecimento à população, suscitar o desejo de aperfeiçoamento.

Especificamente no que toca à graduação em direito, a Resolução CNE/CES no 9 da Câmara de Educação Superior, entidade que compõe o Conselho Federal de Educação, do Ministério da Educação, institui as diretrizes curriculares nacionais para os cursos de graduação em direito.

Em seus artigos $1^{\circ}$ e $2^{\circ}$, a aludida Resolução dispõe que a organização do curso fica a cargo das instituições de ensino que dever observar as diretrizes curriculares nacionais. Cabe às instituições a elaboração do projeto pedagógico devendo abranger entre outras questões (art. $2^{\circ}$ ) "o perfil do formando, as competências e habilidades, os conteúdos curriculares, o estágio curricular supervisionado, as atividades complementares, o sistema de avaliação etc". (grifo nosso).

$\mathrm{O}$ artigo $4^{\circ}$ da Resolução $\mathrm{n}^{\circ} 9$ trata das habilidades e competências necessárias à formação do profissional em direito. Dado a relevância para o estudo proposto, entende-se ser necessária a transcrição do dispositivo: 


\begin{abstract}
Art. $4^{\circ}$. O curso de graduação em Direito deverá possibilitar a formação profissional que revele, pelo menos, as seguintes habilidades e competências:

I - leitura, compreensão e elaboração de textos, atos e documentos jurídicos ou normativos, com a devida utilização das normas técnico-jurídicas;

II - interpretação e aplicação do Direito;

III - pesquisa e utilização da legislação, da jurisprudência, da doutrina e de outras fontes do Direito;

IV - adequada atuação técnico-jurídica, em diferentes instâncias, administrativas ou judiciais, com a devida utilização de processos, atos e procedimentos;

V - correta utilização da terminologia jurídica ou da Ciência do Direito;

VI - utilização de raciocínio jurídico, de argumentação, de persuasão e de reflexão crítica;

VII - julgamento e tomada de decisões; e,

VIII - domínio de tecnologias e métodos para permanente compreensão e aplicação do Direito.(grifos nossos)
\end{abstract}

À luz desses dispositivos, é possível fazer já uma primeira reflexão.

Ressalte-se que as competências e habilidades mencionadas são postas na norma como elementos mínimos para formação do profissional em direito. Esta constatação está claramente evidenciada na expressão "pelo menos", destacada no caput do artigo, a indicar a possibilidade de inclusão de outras competências e habilidades nos projetos pedagógicos dos cursos de graduação em direito.

O outro destaque colocou-se no inciso IV, referente à competência para atuar profissionalmente em instâncias administrativas ou judiciais com utilização de processos, atos e procedimentos. Enquadra-se nesse dispositivo, embora de maneira não explícita, a competência para atuar também em processos ou procedimentos não jurisdicionais. Vale dizer, o ensino de competências necessárias ao preparo do profissional do direito para o manejo dos chamados métodos não jurisdicionais ou alternativos de solução de controvérsias é perfeitamente passível de inclusão nas diretrizes curriculares previstas na Resolução CNE/CES n ${ }^{\circ}$, todavia, como veremos, não parece ser esse o quadro fático atual, ao menos no estado de Sergipe.

Há ainda um outro documento normativo importante a ser analisado. Trata-se do Parecer CNE/CES 150/2013, aprovado em 5 de junho de 2013, mas ainda pendente de homologação. O referido parecer conclui pela necessidade de modificação do artigo $7^{\circ}$ da Resolução $\mathrm{n}^{\circ} 9$, que trata do estágio supervisionado como competente curricular obrigatório à formação do profissional em direito. Com efeito, no que pertine ao tema em estudo, o Parecer prevê a inclusão do $\S 4^{\circ}$ ao supracitado artigo, dispondo, entre outros assuntos, o núcleo de prática jurídica das instituições de ensino superior poderão contemplar a participação em atividades de arbitragem, conciliação e mediação. Essa é a primeira norma de âmbito nacional 
a prevê expressamente a inclusão desse tema nas diretrizes curriculares. Não obstante, como se verá, no estado de Sergipe o ensino dos métodos alternativos de solução de conflitos parece ainda não ter logrado alcançar o destaque merecido por parte das instituições de ensino superior.

\subsection{Um panorama do ensino dos métodos diferenciados de resolução de conflito nos cursos de direito no Brasil.}

Em estudo feito por Gaio Júnior e Ribeiro (2010-1), foram analisados os cursos de direito existente nas trinta e uma maiores instituições de ensino superior no país, levando em consideração o número de alunos matriculados segundo o relatório técnico INEP 2008. Foram verificadas dentre essas, as que possuíam graduação em direito e disponibilizaram suas matrizes curriculares conforme disposto na portaria 2.864, de 24 de agosto de 2005. Com esses critérios, foram analisadas as matrizes curriculares de vinte e seis instituições de ensino superior, considerando que as demais não preencheram os dois critérios escolhidos pelos autores.

Segundo os autores, 52,8 \% das instituições estudadas não oferecem disciplina ligadas a arbitragem, mediação ou conciliação. Importa dizer que mais da metade das instituições objeto da pesquisa não possuem em sua grade curricular qualquer disciplina relacionada à métodos não jurisdicionais de resolução de conflitos. Outro dado relevante, $26,9 \%$ oferecem alguma disciplina com esse viés e somente 19,2\% tem essas disciplinas como obrigatórias.

Constataram ainda que dentre as instituições de ensino superior estudadas que oferecem disciplinas pertinentes ao tema estudado como matérias obrigatórias, têm maior foco em conciliação mediação e arbitragem. Por seu turno, aquelas que oferecem as disciplinas como optativas relacionadas a métodos diferenciados de resolução de conflitos, possuem uma maior variedade na abordagem, elencando disciplinas como Arbitragem e Mediação, Mediação de Conflitos, Solução de Controvérsias Internacionais, Direito de Arbitragem, Métodos Alternativos de Solução de Conflitos e Arbitragem, Mediação e Conciliação.

Os autores concluem que as instituições de ensino superior não privilegiam o estudo dos meios não contenciosos de resolução de conflitos, estando, destarte, em dissonância do planejamento estratégico feito pelos Tribunais no que se relaciona ao tema, de acordo com as orientações do Conselho Nacional de Justiça. 


\subsection{O estudo dos métodos diferenciados de resolução de conflito nos cursos de graduação em direito no estado de Sergipe.}

Em Sergipe, são sete as instituições de ensino superior que possuem graduação em direito cadastradas no Ministério da Educação. São elas: Faculdade Estácio de Sergipe ESTÁCIO-FASE, Faculdade de Administração e Negócios de Sergipe - FANESE, Faculdade de Aracaju - FACAR, Faculdade Pio Décimo - FPD, Faculdade Sergipana - FASER, Universidade Tiradentes - UNIT e Universidade Federal de Sergipe - UFS. Dado o reduzido número de cursos de direito no estado e tendo em vista que todas as instituições disponibilizam em seus sítios na rede mundial de computadores suas grades curriculares ${ }^{1}$, foi possível fazer o estudo proposto em relação à totalidade dos cursos.

Nessa esteira, percebe-se em Sergipe que as faculdades FASER e FACAR ofertam a disciplina Métodos Alternativos de Resolução de Conflitos (FASER, 2015 - FACAR, 2015), de cunho genérico e abrangente; enquanto a ESTÁCIO-FASE (ESTÁCIO-FASE, 2015), possui em sua grade curricular duas matérias eletivas, quais sejam, Mediação de Conflitos e Técnica em Psicologia e Mediação de Conflitos, mais específicas e menos abrangentes.

Como se observa, em termos percentuais a situação do estado de Sergipe é ainda mais deficitária do que o panorama nacional apontado no estudo supracitado. Apenas 42,85\% dos cursos de graduação em direito existentes no estado oferecem alguma disciplina relacionada a métodos diferenciados de resolução de conflitos, enquanto $57,14 \%$ não possui disciplinas ligadas ao tema. Destas, apenas duas o fazem como matéria obrigatória, Faculdade de Sergipe - FASER e Faculdade de Aracaju - FACAR e uma como disciplina eletiva, Faculdade Estácio de Sergipe - ESTÁCIO-FASE Faculdade Estácio de Sergipe - ESTÁCIO- FASE.

\section{COMPETÊNCIAS E HABILIDADES NO ENSINO}

\subsection{Algumas posições doutrinárias acerca de competências e habilidades}

Não há unicidade na doutrina especializada acerca dos conceitos de habilidades e competências. Para Bordoni (sem data) competência seria a "capacidade de bem realizar uma tarefa, ou seja, de resolver uma situação complexa", enquanto habilidade estaria ligada ao "emprego de atitudes, adequadas à realização de tarefas e conhecimentos." Já para

\footnotetext{
1 Os dados referentes às grades curriculares das instituições de ensino superior pesquisadas foram colhidos em sítios próprios na internet, cujos endereços eletrônicos encontram-se nas referências. Há alguma dificuldade em encontrar os dados, pois não existe uniformidade entre as instituições, cada uma utilizando-se de modelo próprio. Algumas disponibilizam os dados na própria página inicial do sítio, em html, enquanto outras possibilitam a captura dos arquivos em pdf.
} 
Perrenoud (1999, p. 4) competência seria "uma capacidade de agir eficazmente em um determinado tipo de situação, apoiada em conhecimentos, mas sem limitar-se a eles." Para esse autor, a habilidade estaria ligada a sequência de modos operatórios, analogias, intuições etc que se faz de modo rotineiro e esquematizado.

Em outra visada, pode-se definir "por competências no ensino do Direito o conjunto de conhecimentos acerca do conteúdo, especificamente do conteúdo jurídico, incluindo o conhecimento da legislação, da doutrina, da jurisprudência e de outras fontes."(Domingues, 2003, p. 77). E conclui entendendo que ““as competências e habilidades” do bacharel em Direito implica, além de dotá-lo do conhecimento do conteúdo jurídico (competências) e de suas fontes, também prepará-lo para a adequada utilização desse conteúdo (habilidades).(Domingues, 2003, p. 78)

Segundo Abrão e Torelly (sem data, p. 9), pode-se classificar as habilidades e competências entre as sociais, comunicativas e instrumentais; todas elas aplicáveis ao campo do estudo do direito.

As competências e habilidades sociais seriam as que pertinem ao entendimento das relações sociais e de poder, bem como as que dizem respeito à capacidade de trabalhar inserido em um grupo. As Comunicativas são aquelas relativas à capacidade expressão, compreensão, raciocínio e análise criticas, são também as referentes a capacidade argumentativa. Por fim, as de cunho instrumental, seriam as relativas ao domínio de técnicas e saberes profissionalizantes e especializados, bem como correta utilização de linguagem específica.

De qualquer sorte, é certo que para o cumprimento de tarefas e resolução de situações problemas diversos, há de se aprender e, portanto, as instituições de ensino devem ensinar, competências e habilidades diversas. E nesse aspecto, não há dúvida que o conjunto de competências necessárias ao desenvolvimento de processos e procedimentos não jurisdicionais e não contenciosos de resolução de disputa, especialmente a conciliação e a mediação, é diverso daqueles utilizáveis no processo e procedimento jurisdicional contencioso. Daí que se se pretende um incremento desses modos de administração de controvérsias, há que se preparar o profissional do direito para esse desiderato. E não existe outro lugar mais adequado para, ao menos, dar início a essa preparação que não sejam as instituições superiores de ensino, particularmente, os cursos de graduação em direito. Afigurase curial que os cursos de graduação em direito encampem essa preparação, ao menos, tanto uanto o fazem na preparação do profissional para laborar no processo jurisdicional contencioso. 


\subsection{Das competências e habilidades necessárias aos métodos diferenciados de resolução de conflitos - mediação e conciliação.}

Quais seriam então as competências e habilidades necessárias ao bom desempenho dos métodos diferenciados de resolução de conflitos? A par o instituto da arbitragem, que por ser um método heterocompositivo as habilidades e competências não diferem sobremaneira das aplicadas ao processo jurisdicional contencioso, afiguram-se mais discrepantes e, por isso, mais dignas de nota no que se refere ao objeto da presente reflexão, as competências e habilidades inerentes ao conciliador e mediador. E ainda em relação a estes, por seu maior grau de aprofundamento, decorrente da própria natureza do instituto, como anteriormente mencionado, afigura-se mais importante detalhar as competências e habilidades necessárias ao bom desempenho da mediação. É o que ser pretende sintetizar.

Para Azevedo (2013), a formação do mediador exige não só um curso teórico, mas também estágio supervisionado por mediador experiente. A formação deve ser apta a transferir aos alunos os métodos de utilização das técnicas necessárias ao desempenho da função de mediador.

O mediador deve ter em mente que a depender da necessidade de cada contenda ele deverá aplicar uma ou mais técnicas autocompositivas, tendo que, para isso, ter conhecimento dessas técnicas. A escuta do mediador deve ser qualificada e também baseada em técnicas específicas.

O mediador deve ser alguém que inspire respeito e confiança das partes devendo saber estimulá-las a alcançar soluções capazes de conciliar interesses, mesmo que aparentemente contrapostos. Para isso deve ter sempre em mente a possibilidade de apresentar perspectivas conciliatórias, motivando os contendores a encontrar soluções sem atribuir culpa a qualquer deles.

Para chegar a esse desiderato, deve estimular a criação de condições tendentes à reformulação de questões diante de eventuais impasses, abordando todos os pontos que possam estar influenciando relação das partes, ainda que não juridicamente tuteladas.

Enfim, não é difícil constatar, mesmo sem um aprofundamento maior, que foge ao objeto deste trabalho, a existência de uma distância significativa entre as competências e habilidades necessárias ao desempenho de papéis em um procedimento jurisdicional contencioso e nos métodos diferenciados de resolução de conflitos, especialmente na mediação e conciliação. 
Nas palavras de Egger:

Quanto ao papel do mediador, poder-se-ia dizer que é, em muitos pontos, similar ao do terapeuta.

$\mathrm{Na}$ mediação se estabelecem vínculos, transferências e contratransferências que exigem do mediador uma intervenção similar a do vínculo psicanalítico. Espera-se do mediador uma escuta similar a do psicanalista ou a de um analista institucional. Uma intervenção sobre o discurso dos outros em conflito, que respeite os tormentos de desejos, que não são os do mediador.

A escuta mediadora deve poder sentir o que se diz e o que não se diz quando se diz algo, ou que outra coisa se está querendo dizer quando se diz algo.

Também poder (saber) escutar, sem sua própria história de desejos reprimidos, o que se quer realmente quando se afirma querer algo. $\mathrm{O}$ mediador precisa saber escutar as outras coisas do querer.

A partir da escuta analítica não se pretende dizer ao analisado o que tem que decidir ou fazer. Trata-se de uma ajuda para que o outro possa reconhecer e decidir. Intervir sobre um objeto de desejo, que muitas vezes, não se faz visível, se torna indizível, responde em última instância, a outro objeto de desejo inacessível.

Muitos conflitos que precisam ser mediados vão ao encontro não manifestado dos efeitos dos objetos primordiais do desejo. A nostalgia da primeira mamada está presente, de alguma maneira, em todo conflito mediável. (Egger, 2008, p. 187/188).

Mais do que um nova abordagem em relação às competências e habilidades, o ensino dos métodos diferenciados de resolução de conflitos parece exigir uma mudança de paradigma, no sentido de não só de novas técnicas, mas um novo olhar sobre a resolução dos conflitos.

\section{CONCLUSÃO}

O mundo não é. O mundo está sendo. Como subjetividade curiosa, inteligente, iterferidora na objetividade com que dialeticamente me relaciono, meu papel no mundo não é só o de quem constata o que ocorre mas também o e de quem intervém como sujeito de ocorrências. Não sou apenas objeto da História mas seu sujeito igualmente. No mundo da História, da cultura, da política, constato não para me adaptar mas para mudar.(Freire, 2005, p. 76/77).

“Ensinar exige a convicção de que a mudança é possível”(Freire, 2005, p. 76) dá nome ao trecho de onde se extraiu texto acima transcrito. Com ele Paulo Freire opina de forma impositiva acerca da necessidade de constatação do que é para buscar o que pode ser. E é nessa linha que se pretendeu propor a reflexão aqui trabalhada.

Não é razoável pensar um curso de graduação em direito distanciado das questões, problemas e situações inerentes à tentativa de aplicação do objeto de estudo, o próprio Direito. E dentre as várias problematizações experimentáveis pela sociedade no que pertine ao mundo jurídico, o do acesso à justiça é, sem dúvida, um dos que mais afligem as pessoas. 
Tanto que é objeto de estudos há bastante tempo, tendo a doutrina apontado uma evolução em seu conceito e sua caracterização, conforme se assinalou acima. E na seara do atual estágio da ideia de acesso à justiça, como efetivo e adequado tratamento do conflito e de sua solução, não há como prescindir dos métodos diferenciados de resolução de contendas. A rigor, a história tem evidenciado que o tradicional método jurisdicional contencioso não é suficiente para abarcar todas as possibilidades de conflitos juridicamente relevantes e muito menos de dar uma resposta adequada a eles.

Nessa senda, a doutrina e legislação têm apontado novos caminhos a serem percorridos para uma adequada solução das controvérsias sociais, no intuito de efetivar concretamente o almejado princípio do acesso à justiça. E, conforme constatado, embora iniciativas oriundas dos Poderes Judiciário e Legislativos tenham sido implementadas para privilegiar e viabilizar a aplicação de métodos diferenciados de resolução de conflitos, a academia tem ficado para trás nessa caminhada. Conforme se verificou, ainda é tímido o movimento no sentido de se estudar esses métodos nas instituições de ensino superior, especialmente em nível de graduação.

Ocorre que é, se não totalmente, mas principalmente, nas academias que se forja a cultura jurídica de um país. Vale dizer, se a tendência demandista existente hoje nos profissionais do direito está posta, é muito em virtude do ensino jurídico na forma que é apresentado nas faculdades de direito. E se a pretensão é de mudar essa cultura, na esteira do movimento judicial e legislativo em curso, é de suma importância que se dê uma maior ênfase ao estudo dos métodos alternativos de solução de contendas nos cursos de graduação em direito. Ressalve-se que, embora esteja fora do objeto deste estudo, parece evidente constatar que a academia não está completamente distante do referido movimento. Afigura-se plausível inferir que se há um movimento no sentido de mudanças significativas no mundo do direito (Leis, jurisprudência etc) há de partir em grande medida da intelectualidade que está nas academias. É certo, outrossim, que existem significativos estudos em nível de pós-graduação que inclusive subsidiam o Legislativo e Judiciário, alguns apontados neste texto, mas, repita- se, não é o escopo desta reflexão. O que se propõe aqui é refletir acerca da necessidade de incluir de maneira mais densa e incisiva o estudo ora referido em nível de graduação em direito. Só assim, pensa-se, será possível a capacitação necessária e, principalmente, a modificação do paradigma cultural existente para a solução dos conflitos, de modo a efetivar o princípio constitucional do acesso à justiça. 


\section{REFERÊNCIAS}

ABBAGNANO, Nicola. Dicionário de Filosofia. São Paulo: Martins Fontes, 2014.

ABRÃO, Paulo e TORELLY, Marcelo Dalmás. As Diretrizes Curriculares e o Desenvolvimento de Habilidades e Competências nos Cursos de Direito: O Exemplo Privilegiado da Assessoria Jurídica Popular. Disponível em: <http://egov.ufsc.br/portal/sites/default/files/anexos/32421-39149-1-PB.pdf>. Acesso em: 14 ago. 2015.

AZEVEDO, André Goma de (Org.). Guia de Conciliação e Mediação Judicial para Magistrados. Brasília: ENAM - Ministério da Justiça, 2013.

BARBADO, Michelle Tonon. Reflexões sobre a institucionalização da mediação no direito positivo brasileiro. In: Estudos em Arbitragem, Mediação e Negociação Vol 3 / André Gomma de Azevedo (org.) - Brasília: Grupos de Pesquisa, 2004. Disponível em: $<$ http://www.arcos.org.br/livros/estudos-de-arbitragem-mediacao-e-negociacao-vol3/parte-iidoutrina-parte-especial/reflexoes-sobre-a-institucionalizacao-da-mediacao-no-direitopositivo-brasileiro/> Acesso em: 16 ago. 2015

BARROSO, Luiz Roberto. Curso de direito constitucional contemporâneo: os conceitos fundamentais e a construção do novo modelo. 4.ed. São Paulo: Saraiva, 2013.

BORDONI, Tereza. Saber fazer. Competências e Habilidades. Disponível em: <http://www.pedagobrasil.com.br/pedagogia/saberefazer.htm>. Acesso em: 16 ago. 2015.

BRASIL. Constituição da República Federativa do Brasil. Diário Oficial da República Federativa do Brasil, Brasília, DF, 5 ou. 1988. Disponível em <http://www.planalto.gov.br/ccivil_03/constituicao/constituicao.htm>. Acesso em: 11 ago. 2015 .

BRASIL. Lei ${ }^{\circ}$ 13. 105, de 16 de março de 2015. Novo Código de Processo Civil. Diário Oficial da República Federativa do Brasil, Brasília, DF, 13 mar. 2015. Disponível em: <http://www.planalto.gov.br/ccivil_03/_Ato2015-2018/2015/Lei/L13105.htm>. Acesso em: 13 ago. 2015.

BRASIL. Lei ${ }^{\circ}{ }^{\circ} 13.140$, de 26 de junho de 2015. Dispõe sobre a mediação entre particulares como meio de solução de controvérsias e sobre a autocomposição de conflitos no âmbito da administração pública; altera a Lei no 9.469, de 10 de julho de 1997, e o Decreto no 70.235, de 6 de março de 1972; e revoga o $\S 2$ o do art. 6 o da Lei no 9.469, de 10 de julho de $1997 .$. Diário Oficial da República Federativa do Brasil, Brasília, DF, 29 jun. 2015. Disponível em: < http://www.planalto.gov.br/ccivil_03/_Ato2015-2018/2015/Lei/L13140.htm>. Acesso em: 13 ago. 2015.

BRASIL. Lei n ${ }^{\circ}$ 9.307, de 23 de setembro de 1996. Dispõe sobre arbitragem. Diário Oficial da República Federativa do Brasil, Brasília, DF, 24 set. 1996. Disponível em: < http://www.planalto.gov.br/ccivil_03/leis/L9307.htm>. Acesso em: 13 ago. 2015. 
EGGER, Ildemar. Mediação comunitária popular: uma proposta para além da conflitologia. 2008. 496 p. TESE (Doutorado em Direito). Curso de Ciências Jurídicas. Universidade Federal de Santa Catarina. Florianópolis, 2008.

ESTÁCIO - FASE, Faculdade Estácio de Sergipe. Grade Curricular. Disponível em: <http://portal.estacio.br/media/4503331/matriz\%20curricular\%20de\%20direito.pdf> Acesso em: 30 jul. 2015

FACAR, Faculdade de Aracaju. Grade Curricular. Disponível em: <http://www.unilist.com.br/facar/ensino/graduacao/tradicionais/direito.asp>. Acesso em: 30 jul. 2015.

FANESE, Faculdade de Administração e Negócios de Sergipe. Grade Curricular. Disponível em: <http://portal.fanese.edu.br/?page_id=196> Acesso em: 30 jul. 2015.

FASER, Faculdade Sergipana. Grade Curricular. Disponível em: <http://www.faserse.edu.br/ensino/graduacao/tradicionais/direito.asp>. Acesso em: 30 jul. 2015.

FPD, Faculdade Pio Décimo. Grade Curricular. Disponível em: <http://www.piodecimo.com.br/curso/2/43839/matriz-curricular.html>. Acesso em: 30 jul. 2015.

FREIRE, Paulo. Pedagogia da Autonomia: Saberes Necessários à Prática Educativa. 31. ed. São Paulo: Paz e Terra, 2005.

IHERING, Rudolf Von. A Luta pelo Direito. 23. ed. Rio de Janeiro:Martin Claret Ltda., 2004.

LEDERACH, Jonh Paul. Transformação de Conflitos. São Paulo: Palas Athena, 2012 (Da Reflexão À Ação)

NASCIMENTO, Joelma Gomes do. Mediação: Meio alternativo para solução de conflitos. In: Âmbito Jurídico, Rio Grande, XIV, n. 84, jan 2011. Disponível em: <http://www.ambitojuridico.com.br/site/index.php?n_link=revista_artigos_leitura\&artigo_id=8921>. Acesso em: 16 ago. 2015.

SADEK, Maria Tereza Aina. Acesso à justiça porta de entrada para a inclusão social. In LIVIANU, R., cood. Justiça, cidadania e democracia [online]. Rio de Janeiro: Centro Edelstein de Pesquisa Social, 2009. Disponível em: <http://books.scielo.org/id/ff2x7/pdf/livianu-9788579820137-15.pdf> . Acesso em: 16 ago. 2015.

SANTOS, Ricardo Soares Setersi dos. Mercosul e Arbitragem Internacional e Comercial: Aspectos Gerais e Algumas Possibilidades. Belo Horizonte: Del Rey, 1998.

UFS, Universidade Federal de Sergipe, Departamento de Direito. Grade Curricular. Disponível em:<https://www.sigaa.ufs.br/sigaa/public/departamento/componentes.jsf?id=98>. Acesso em: 30 jul. 2015.

UNIT, Universidade Tiradentes. Grade Curricular. Disponível em: <http://www.unit.br/cursos/cursos-graduacao/direito/>. Acesso em: 30 jul. 2015. 